\title{
Coronary Artery Bypass Graft in a Patient with Markedly Reduced Ejection Fraction
}

\author{
Asit Baran Adhikary' \\ Kamrul Ahsan ${ }^{2}$ \\ Sabrina Sharmeen Husain \\ Sanjoy Kumar Saha ${ }^{3}$ \\ Arif Mohammad Sohan \\ Md Nazmul Hasan ${ }^{4 *}$
}

'Department of Cardiothoracic Surgery

Bangabandhu Sheikh Mujib Medical University Dhaka, Bangladesh.

${ }^{2}$ Department of Cardiothoracic Surgery National Institute of Cardiovascular Diseases Dhaka, Bangladesh.

${ }^{3}$ Department of Anaesthesiology

Bangabandhu Sheikh Mujib Medical University Dhaka, Bangladesh.

${ }^{4}$ Department of Cardiology

Bangabandhu Sheikh Mujib Medical University Dhaka, Bangladesh.

\section{*Correspondence to:}

\section{Dr. Md Nazmul Hasan}

Resident

Department of Cardiology

Bangabandhu Sheikh Mujib Medical University

Shahbag, Dhaka, Bangladesh.

Mobile: +8801675755638

E-mail: nazmulhasan45cmc@gmail.com

\begin{abstract}
Coronary artery bypass grafting has always given advantage over medical management in treating ischaemic heart disease when 5 years survival is concerned. But, surgery is usually avoided in patients with ischaemic cardiomyopathy with low ejection fraction due to perioperative mortality .Here, we are presenting a case of first successfully performed CABG in Bangladedesh in a patient with ejection fraction of $19 \%$. A 58 years old diabetic and hypertensive male patient, having history of myocardial infarction was suffering from ischaemic cardiomyopathy. He presented with compressive central chest pain, dyspnoea and fatigue and was in NYHA functional class IV. His coronary angiogram revealed tripple vessel coronary artery disease and there was severe left ventricular systolic dysfunction on Echocardiography. On $11^{\text {th }}$ June, 2013 he underwent off pump coronary artery bypass graft where 3 grafts were anastomosed on beating heart. There was no peroperative complication and no need for perioperative IABP. Weaning time from ventilation and period of inotropic support were not longer than usual that is required for a patient with normal ejection fraction. Patient's postoperative period was unremarkable. After six months follow up, his ejection fraction had improved to $26 \%$ and on nine months follow up his ejection fraction was $35 \%$. The patient is apparently symptom less, resumed his job and leading an almost normal life. Therefore, surgery in a skilled hand can combat perioperative mortality and morbidity and gives better result in patient with low ejection fraction.
\end{abstract}

Key words : Coronary artery; Ejection fraction; Ischaemic heart disease.

\section{INTRODUCTION}

Management of patients of coronary artery disease with low ejection fraction has three options-medical management, coronary artery bypass surgery and heart transplantation. Several studies have shown, medical management alone has lower long term survival rate in this group compared to surgical procedure ${ }^{1-5}$. In contrast, in patients undergoing $\mathrm{CABG}$ in recent years registered better result. Despite this fact ,physicians are still reactant in recommending these patients for surgery. This is because of higher rate of perioperative mortality in this group ${ }^{6}$.

Increased incidence of perioperative mortality in these groups are due One study has shown $4 \%$ higher mortality in surgical group in compare to medical treatment group ${ }^{7}$. Post operative mortality and morbidity is evidently \& reasonably higher in patients with low ejection fraction undergoing $\mathrm{CABG}^{3,6-7}$. to sudden cardiac death, heart failure, shock, post operative stroke, perioperative MI,renal failure, respiratory failure and sepsis. There are also frequent needs for IABP and reopening. There are certain predictors of morbidity and mortality in this group. Here, we are going to describe a case of ischaemic cardiomyopathy having ejection fraction less than $20 \%$ who has underwent off pump CABG.

$w w w . c m o s h m c j . \circ r g$ 
This for the first time in Bangladesh, so far we know, surgery has been performed in a patient having pre operative ejection fraction below $20 \%$. According to the functional classification he was included in NYHA class IV. In Bangladesh, the leading CABG operators have been working in a non Government sectors always look for the cases which has lowest post operative risk. On the other hand, physicians have been trusted their cases with low ejection fraction very little for giving the options for surgery. The first author has performed this case in Shikder cardiac centre and research centre where the outcome was excellent with least perioperative mortality.

\section{CASE REPORT}

The patient, a 58 years old smoker was a known case of diabetes mellitus, hypertension and dyslipidaemia. He gave history of acute myocardial infarction for two times in last 2 years. He presented with the complaints of central compressive chest pain and shortness of breath during rest. He also complained of fatigue and generalized weakness. His symptoms were not under control even after optimum medical management. His decision of revascularization was pending because of the fact that the patient has ejection fraction $19 \%$. The only remaining option of our first author was to give the patient an choice of surgery and counsel the patient properly to take the substantial risk of $\mathrm{CABG}$ as he was suffering from triple vessel disease involving left anterior descending, circumflex and right coronary artery.

His physical examination reveals, dyspnoea and mild anemia. Pulse 98/min, BP 90/60 mm of Hg, muffled heart sound, lung bases were full of crackles. Investigation before surgery showed $\mathrm{Hb} 12 \mathrm{gm} / \mathrm{dl}$, FBS $7.5 \mathrm{mmol} / \mathrm{L}$, Serum creatinine $1.2 \mathrm{mg} / \mathrm{dl}$, serum Total cholesterol $255 \mathrm{mg} / \mathrm{dl}$, LDL $188 \mathrm{mg} / \mathrm{dl}$, HDL 25 $\mathrm{mg} / \mathrm{dl}$. ECG showed old anterolateral MI.CXR showed cardiomegaly. According to Echocardiography, LVIDd $67 \mathrm{~mm}$, LVIDs $61 \mathrm{~mm}$, LVFS 9.2\%,LVEF 19\%,IVS was $5.2 \mathrm{~mm}$. The anterior wall and interventricular septum was thin and akinetic. Rest of the wall showed moderate hypokinesia. Final comment was old MI with ischaemic cardiomyopathy with severe LV systolic dysfunction. Coronary angiogram finding reveals $90 \%$ stenosis in proximal LAD, $70 \%$ stenosis in RCA \& $80 \%$ stenosis in LCX.

The patient underwent off pump CABG on 11th of June, 2013.Left internal mammary artery, left radial artery and great saphanous vein were harvested. LIMA was anastomosed to LAD $(1.5 \mathrm{~mm})$. Two proximal anastomosis of LRA and RSV to aorta. Distal anastomosis of RSV to PDA was done after atherectomy. LRA was anastomosed distally to OM2 (1.5 $\mathrm{mm})$.All anastomosis were done on beating heart. Heart stabilized with starfish and octopus stabilizer during distal anastomosis. After achieving homeostasis chest was closed leaving one RV epicardial pacing wire and three chest drain tubes -one in left pleura, one in right pleura \& one in retrosternal area.
Peroperative and early postoperative period was uneventful. There was no perioperative MI, arrythmia,shock and low output syndrome. Patient was extubated 8 hours after transfer to ICU and inotropic support continued for 3 days. There was no need for pacing. Post operative bleeding was mimimum and drain tube was off on 3rd POD. He was discharged from hospital on 9th POD.

Follow up visit after 4 week, patient showed significant symptomatic improvement. He was free of chest pain though there was exertional shortness of breath. At 6 months follow up patient shows further improvement and he was essentially symptom free. he has joined his job and leading a normal life without any complaints. His vital signs and biochemical parameters were normal and Echocardiography shows left ventricular internal diameter $68 \mathrm{~mm}$ in diastole, FS 12\%, EF 26\%.

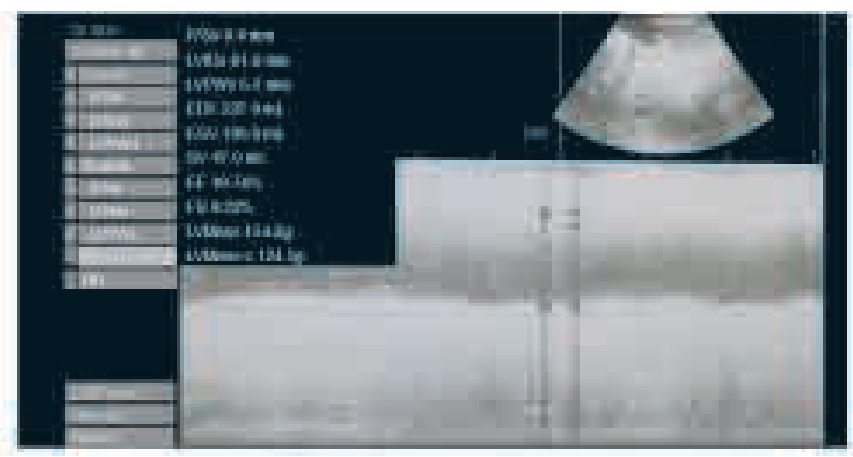

Figure 1: Preoperative Transthoracic echocardiography Showing $19 \%$ ejection fraction

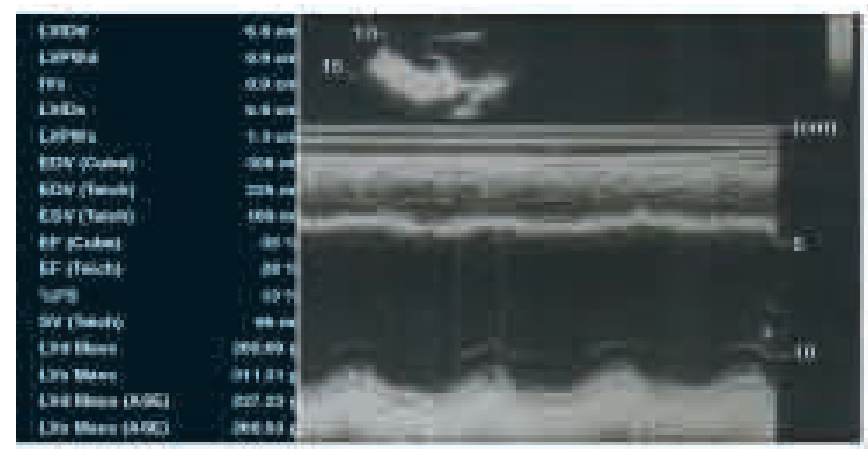

Figure 2: Transthoracic echocardiography after 9 months of operation Showing 28\% ejection fraction

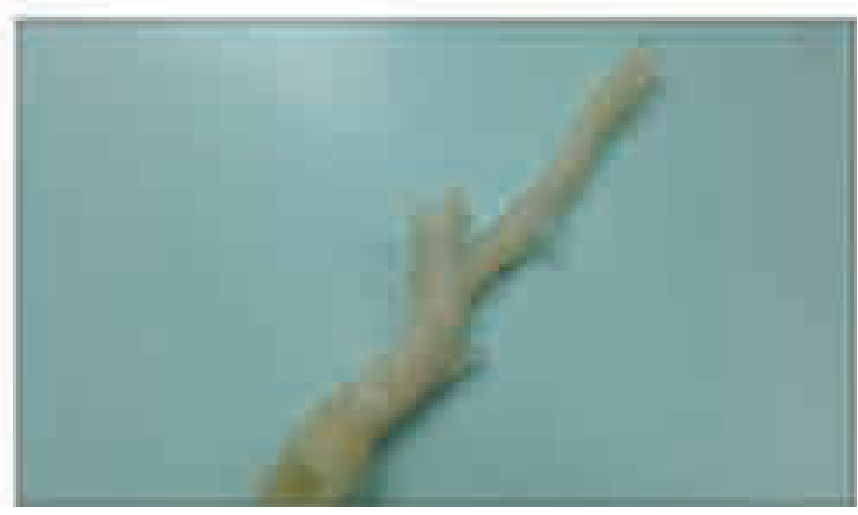

Figure 3 : Atheroma removed from Right Coronary artery (RCA) 


\section{DISCUSSION}

Coronary artery surgery (CAS) study shows that, only $38 \%$ of medically treated patients with low ejection fraction $(<35 \%)$ were alive without symptoms after 5 years of starting optimum medical management ${ }^{5}$. In contrast, in surgical group which comprises $\mathrm{CABG}$, ventricular remodeling and cardiac transplantation has $82 \% 5$ years survival rate $^{6}$. One of the reasons for this significantly higher survival rate in surgical group is due to high survival in cardiac transplant group. But, in a developing country like Bangladesh, where there is limited opportunity for cardiac transplantation and shortage of donor organ is one of the important attributes. Several studies have demonstrated, CABG in patients with low ejection fraction is to be superior than medical management alone. In a study done by Alderman et el reported that, patient with $\mathrm{EF}<30 \%$ undergoing CABG has $63 \% 5$ years survival rate in compare to $43 \%$ survival in patients who were managed medically. Despite this distinct advantage of long term survival in the CABG group, surgery is often less performed because of higher perioperative mortality. Topkara VK et el reported 4 times higher mortality in patients with low ejection fraction than with normal ejection fraction ${ }^{6}$.

The characteristics of operative details in the patients of cardiomyopathy are; requiring higher frequency of urgent surgery, need for skilled operator who can perform off pump bypass confidently. In these cases use of heart lung machine adds further risk because of failure to wean from bypass due to extracorporeal circulation induced myocardial depression .Causes of increased perioperative mortality and morbidity includes shock, stroke, LOS, arrhythmia, heart failure, wound infection and sepsis. There are increased rate of reoperation due to bleeding, renal failure, respiratory failure and frequent use of IABP.
In our patient, the patient was operated without using the pump which is ideal for this group. Atherectomy done successfully and this added an excellent benefit. The operative time was 6 hours which was almost same as the time taken for a patient with normal LV function although operations in these patients need longer time usually. Our patient did not required prolonged ventilation or high ionotropic support. This patient did not suffer from LOS, arrhythmia, post operative bleeding which are usually encountered in this type of patients. There are some attributes of poor outcome in patients with low EF\% undergoing $\mathrm{CABG}$; they are age, NYHA functional class, renal function, respiratory function ${ }^{8}$. Our patient had some of the attributes like NYHA class 4 and DM.

ne study has shown decreased GFR is only determinant factor for poor outcome in Our first author has controlled the pre operative blood sugar level by short acting insulin and improved lung function by breathing exercise and intensive spirometry. Anti failure drugs were given .So that, the patient had eventless postoperative period and improvement was functional and echocardiographic. Patient with low EF\%and in our patient it was normal so, it was another important factor of better result ${ }^{9-10}$.

In a country like Bangladesh, where auxiliary supports are often sparse and surgeons have general trend to avoid complicated cases; our first author has performed this surgery with successful outcome. The reason behind the success is surgeon's expertise of performing off pump bypass and experience to deal the probable clinical squeal. Furthermore, since the bypass was aided by Atherectomy it added better prognosis. In expert hand, patients of low Ejection Fraction may undergo CABG to improve survival and quality of life.

\section{DISCLOSURE}

All the authors declared no competing interest.

\section{REFERENCES}

1. Alderman EL, Fisher LD, Litwin P. Kaiser GC. Myers WO, Maynard C, Levine F, Schloss M. Results of coronary artery surgery in patients with poor left ventricular function (CASS). Circulation. 1983; 68:785-795.

2. Scott SM, Deupree HL, Sharma GVRK, Luchi RJ. VA study of unstable angina. 11-year results show duration of surgical advantage for patients with impaired ejection fraction. Circulation. 1994; 90(suppl II):120-123.

3. Zubiate P, Kay JH, Mendez AM. Myocardial revascularization for the patient with drastic impairment of function of the left ventricle. J Thorac Cardiovasc Surg. 1977; 73:84-86.

4. Di Carli MF. Maddahi J. Rokhsar S, Schelbert HR, Bianco-Baffles D, Brunken RC. Fromm B. Long-term survival of patients with coronary artery disease and left ventricular dysfunction: implications for the role of myocardial viability assessment in management decisions. J Thorac Cardiavasc surg. 1998; 116:997-1004.

5. Passamani E, Davis KB, Gillespie MJ, Killip T. A randomized trial of coronary artery bypass surgery. Survival of patients with a low ejection fraction. N Engl J Med. 1985:312:1665-1671.

6. Topkara VK, Cheema FH, Kesavaramaryam S, Mercando ML, Cheema AF, amerow PB. Argenziano M. Maka Y. Oz MC. Esrig BC Coronary artery bypass grafting in patients with low ejection fraction. Circulation. 2005;112 ( suppl):1344-1350.

7. Velazquez EJ, Lee KL, Deja MA, Jain A, Sopko G, Marchenko A, Ali IS, Pohost G, Gradinac S, Abraham WT, Yii M, Prabhakaran D, Szwed H, Ferrazzi P, Petrie MC, O'Connor CM, Panchavinnin P, She L, Bonow RO, Rankin GR, Jones RH, Rouleau JL; STICH Investigators. Coronary-artery bypass surgery in patients with left ventricular dysfunction. N Engl J Med. 2011; 364(17):1607-1616.

8. Graham SH, Kenton JZ, Amy WW, Hartzell VS, Thomas AO, Richard CD, Charles JM, Richard JR. Outcome of patients with low EF undergoing coronary artery bypass grafting: Renal function and mortality after 3.8 years. Circulation 2006; 114:1-414-419.

9. Wenger NK. Left ventricular dysfunction, exercise capacity and activity recommendation. European heart journal. 1988; 9(suppl F): 63-66.

10. Francisa JA, Park M, Levine TB. Lack of correlation between exercise capacity and index of LV performance in HF. American Journal cardio. 1981; 47:33-39. 